\title{
The Influence of Fiber Orientation on Crashworthiness Behavior of Carbon Fiber Reinforced Composite Pipes
}

\author{
Özkan Özbek ${ }^{1}$ and Ömer Yavuz Bozkurt ${ }^{2}$ \\ ${ }^{1.2}$ Gaziantep University, Mechanical Engineering Department, 27310, Gaziantep, Turkey.
}

\begin{abstract}
ARTICLE INFO
Keywords:

crushing; filament

winding; composite

material; failure mode;

energy absorption

ABSTRACT

The current paper described an experimental investigation about the effect of fiber orientation angle on the crashworthiness characteristics of carbon/epoxy fiber reinforced composite pipes subjected to quasi-static axial compression. The samples, having three different fiber orientation angles as $\pm\left(40^{\circ}\right), \pm\left(55^{\circ}\right)$ and $\pm\left(70^{\circ}\right)$, were fabricated by filament winding technique. Crushing parameters, in terms of load-displacement response, load carrying capacity, energy absorption capability and mean crushing stress, were determined for each sample. The results showed that the fiber orientation angle were found to have significant influences on crashworthiness of composite pipes. The increase in fiber orientation angle resulted with decrease in energy absorption capability and increase in crushing load efficiency. In the view of specific energy absorption aspect, minimum value of $32.20 \mathrm{~J} / \mathrm{g}$ was obtained in \pm $\left(70^{\circ}\right)$ fiber orientation and improvements up to $46 \%$ were achieved by increasing in orientation angle. Also, detailed investigations on fracture mechanisms were performed to understand failure modes. All samples were exhibited the progressive crushing in types of lamina bending or brittle fracturing.
\end{abstract}

\section{Introduction}

Polymer-based composites using fiber materials have been an attractive option to reinforce a structural components since their higher strength- and stiffness-to-weight ratio, fatigue life compared to classical metallic-based engineering materials. Many fiber reinforcements such as glass fiber, carbon fiber, aramid fiber, basalt fiber and organic fibers are seen in the literature, and different benefits according to usage in applications are presented. In recent years, the use of fiber reinforced tubular composites with thin-walled structures and lightweight characteristics have been rapidly accelerating to increase crashworthiness capability of a product or a system in a crash event. Several methods as hand layup, prepreg winding, filament winding, vacuum assisted resin transfer molding are present to obtain tubular composites in the literature. Among them, filament winding is the best manufacturing method to obtain tubular composites because of ensuring connectionless one piece fiber usage, desired fiber orientation and settlement onto mandrel and

$\square$ Corresponding Author E-Mail Address: ozkanozbek@gantep.edu.tr 
flexibility in design of products. Simply, the technique is based on wrapping a fiber reinforcement on a mandrel and provides the opportunity of easy fabrication of products at different design parameters.

Several studies regarding the crashworthiness of fiber reinforced tubular composites fabricated by filament winding are present in the literature. The effect of winding angles as $\pm\left(45^{\circ}\right)$ and $\pm\left(90^{\circ}\right)$ on the crushing behavior of hollow kenaf fibre and hybrid aluminium/kenaf fibre reinforced unsaturated polyester composites produced by the filament winding technique were studied (Misri et al., 2015). The hollow composites having $45^{\circ}$ winding angle exhibited the more energy in crushing due to their longest distance in the post-crushing zone. In another study (Wang et al., 2016), investigation of the effects of fiber orientation $\left(15^{\circ}, 30^{\circ}, 45^{\circ}, 60^{\circ}\right.$ and $\left.75^{\circ}\right)$ and wall thickness on the energy absorption characteristics of carbon fiber reinforced composite pipes subjected to axial quasi-static loading were examined. The winding angle and thickness showed the significant influences on the crashworthiness characteristics of the progressively crushed pipes. Brittle fracturing and lamina bending as failure modes were observed. The influence of fiber orientation angle on the energy absorption capability of E-glass/epoxy reinforced composite pipes (GFRP) having six different winding angles as $0^{\circ}, 15^{\circ}, 30^{\circ}, 45^{\circ}, 60^{\circ}$ and $75^{\circ}$ and eight layers were conducted (Mahdi et al., 2014). 15\%-75 and $75^{\circ} /-15^{\circ}$ were being recommended for better load carrying and energy absorption capability. A combination of four failure modes as fiber debonding, fiber fracture, matrix cracking and delamination have been observed from samples under progressive crushing. Also, the effect of geometric factor, winding angle and pre-crack angle on quasi-static crushing behavior of filament wound carbon fiber reinforced composite cylinders were examined in another literature study (Jia et al., 2013). The compressive strength, compressive modulus and crack length exhibited the decrease trend and crushing efficiency showed the opposite trend with winding angle increasing.

The aim of current work is to experimentally examine the effect of fiber orientation angle on the crashworthiness behaviors of carbon fiber reinforced composite pipes subjected to quasi-static axial compression in order to provide an effective reference for a system design in engineering applications. Three different fiber orientation angle as $\pm\left(40^{\circ}\right), \pm\left(55^{\circ}\right)$ and $\pm\left(70^{\circ}\right)$ and six number of layers were used to see crushing characteristics of the carbon fiber reinforced tubular structures.

\section{Material and Method}

\subsection{Materials}

The fiber reinforcement used in this study, as seen in Figure 1, is the continuous fiber of Carbon roving having $12 \mathrm{~K}$ linear density (tex) which are procured from Plasto A. Ş., Turkey. The mechanical and physical properties of the carbon fiber reinforcement material are given in Table 1. 
Figure 1: Carbon roving fiber

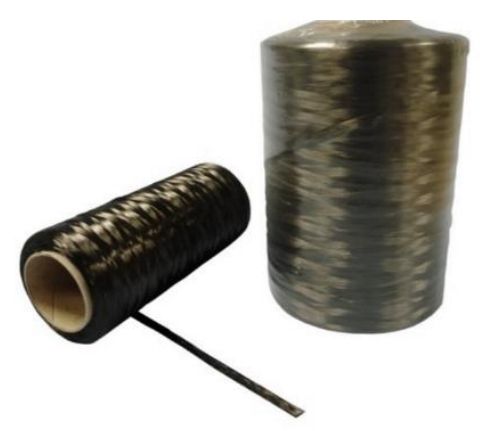

Table 1: Mechanical and physical properties of carbon fiber reinforcement

\begin{tabular}{|c|c|c|c|c|}
\hline $\begin{array}{c}\text { Tensile } \\
\text { Strength } \\
(\mathrm{MPa})\end{array}$ & $\begin{array}{c}\text { Tensile } \\
\text { Modulus } \\
(\mathrm{GPa})\end{array}$ & $\begin{array}{c}\text { Elongation } \\
\text { at break } \\
(\%)\end{array}$ & $\begin{array}{c}\text { Filament } \\
\text { Diameter } \\
(\mu \mathrm{m})\end{array}$ & $\begin{array}{c}\text { Specific } \\
\text { Density } \\
\left(\mathrm{g} / \mathrm{cm}^{3}\right)\end{array}$ \\
\hline 3950 & 238 & 1.5 & 7 & 1.77 \\
\hline
\end{tabular}

For the matrix structure, the epoxy and hardener types allowing 6-7 hours curing time are chosen to avoid the curing issue of epoxy-hardener mixing during the fabrication process. The epoxy (EPIKOTE MGS LR160 resin) and hardener (EPIKURE Curing Agent MGS LH260S), which are supplied from Dost Kimya A.Ş., Turkey, are blended with a stoichiometric weight ratio of 100/35 to form the matrix system.

\subsection{Fabrication of composite pipes}

The filament winding technique, shown in Figure 2, is used to produce all considered pipe samples. The fabrication process of fiber reinforced composite pipes can be categorized into three distinct steps as preliminary preparations, process conducting and post processing. As preliminary preparations, release wax is applied on the mandrel and release agent film is wrapped at first. Afterwards, release wax is again implemented to pull out the mandrel from the pipe at the end of the winding process. The glass wool is exerted to obtain smooth surface inside the samples. Fiber reinforcement is placed with helping of resin bath and rollers. By using epoxy and hardener, resin mixture is prepared and deposited into the resin bath tank. Then the process at desired parameters is begun by loading the motion codes to machine, as seen in Figure 3. 
Figure 2: Filament winding technique

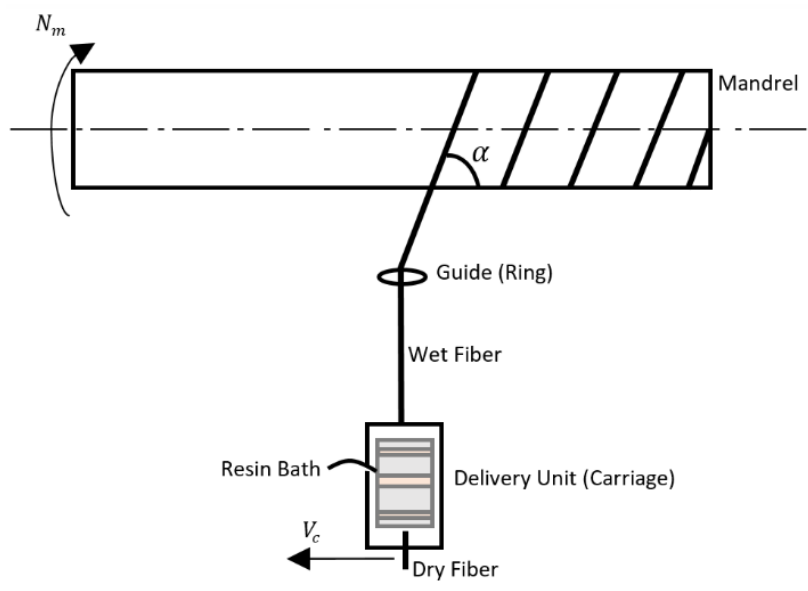

Figure 3: Fabrication of composite pipes

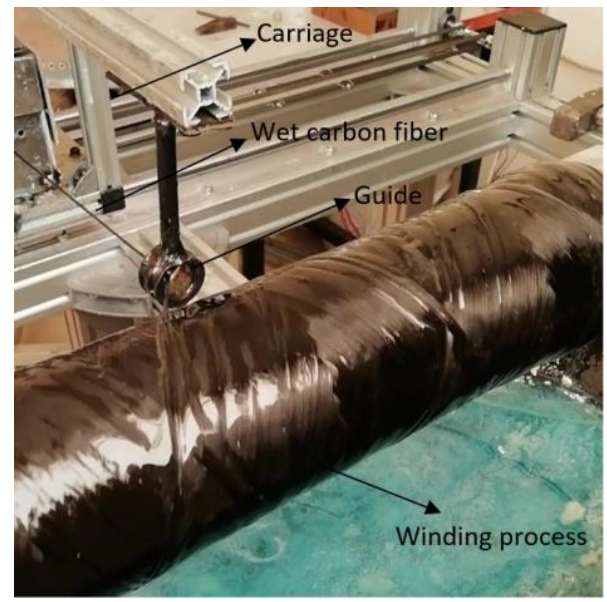

After process is completed, a heat shrinkage tape is wrapped on the mandrel and curing procedure is performed by heating the samples when it is rotating. Sanding and polishing as post processing can be conducted to obtain aesthetic appearance on the sample. The thickness values of the samples were measured as $2.35 \pm 0.08 \mathrm{~mm}$ for all fiber orientations. Also, fiber mass fractions were determined as $57.22 \%, 56.88 \%$ and $56.65 \%$ for $\pm\left(40^{\circ}\right), \pm\left(55^{\circ}\right)$ and $\pm\left(70^{\circ}\right)$ fiber orientation angles, respectively.

\subsection{Quasi-static axial compression}

The axial crushing experiments are performed between two flat steel plates applying quasi-static compression loading, which on a $300 \mathrm{kN}$ capacity Shimadzu AG-X Series universal testing machine, to obtain crashworthiness parameters of composite pipes. All samples are compressed into $32.5 \mathrm{~mm}$ (about $70.2 \%$ stroke efficiency) at a loading rate of $1.3 \mathrm{~mm} / \mathrm{min}$ as shown in Figure 4. The load in crushing process versus displacement of moving platen is recorded by automatic data acquisition system. At least five replicated tests are achieved to ensure experimental reliability 
for both crushing. By the way, photographs are taken by a camera to monitor the crushing process history.

Figure 4: Quasi-static axial compression

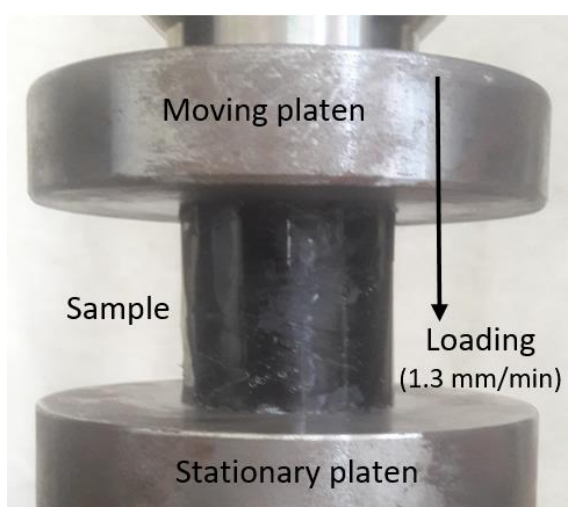

Crushing process, as shown in Figure 5, can be generally divided into three stages as pre-crushing, post-crushing and material densification (Mahdi et al.,2014). In elastic region or pre-crushing, the material behaves elastically that can be returned to original length if loading is removed, and initial peak load is noted. Small inter- or intra-laminar cracks as micro fracture, which determinative of failure mode, are nucleated with local stress concentration on the initial peak load point. After that, post-crushing goes on with propagation of crushing in progressive or catastrophic manner. This stage is the crucial to measure crashworthiness parameters except initial peak load and to understand failure mechanisms. Lastly, when material densification is started which means load increases sharply, crushing process is done.

Figure 5: Quasi-static axial compression

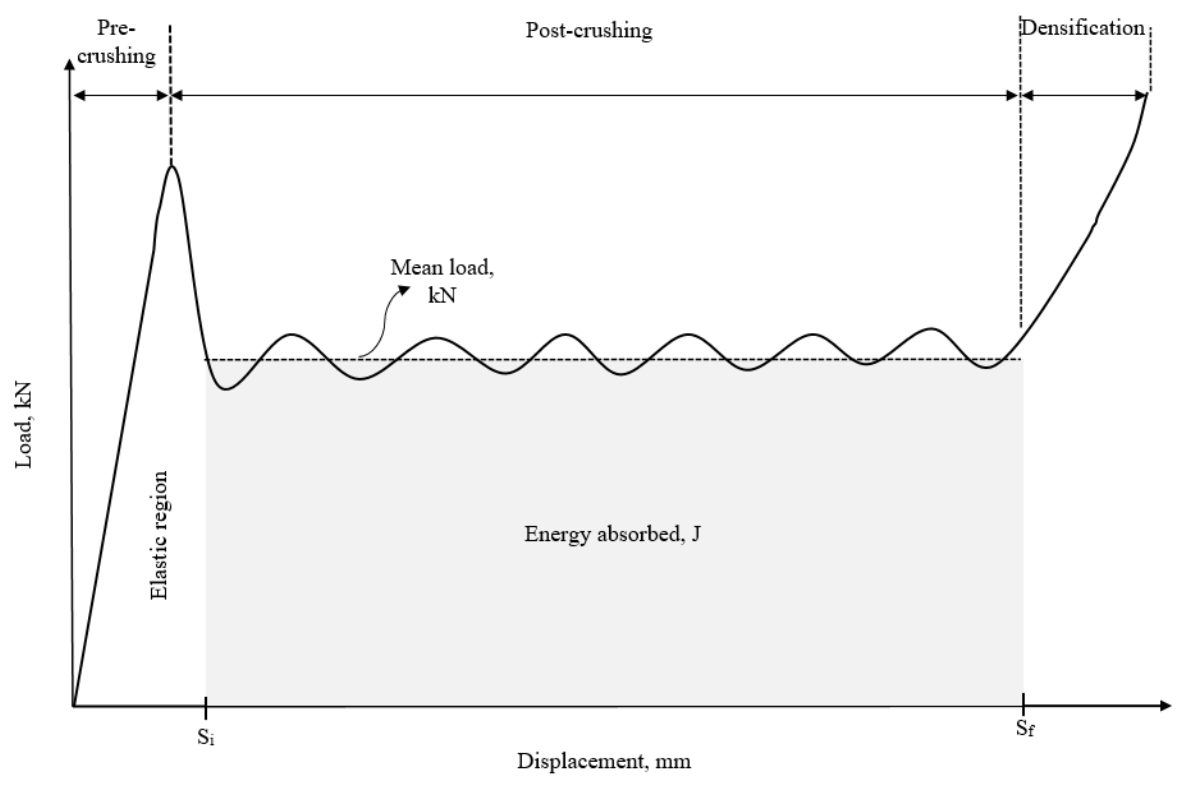


The crashworthiness parameters of fiber reinforced composite pipes are calculated as follows:

Total energy absorption, $\mathrm{E}$ is the area under load-displacement curve between crush distances, which is shown in Figure 5, and calculated by integration of load, P as seen Eqn. (1);

$$
E=\int_{S_{i}}^{S_{f}} P(s) d s
$$

where $S_{i}$ and $S_{f}$ represents the initial and final stroke values in compression after the first initial peak load. Also, mean load is found from the integration of each load value depending on stroke or pipe length, $\mathrm{P}(\mathrm{s})$ in crushing propagation stage as in Eqn. (2);

$$
P_{m}=\frac{\int_{s_{i}}^{S_{f}} P(s) d s}{S_{f}}
$$

Crushing load efficiency, $\eta_{\mathrm{f}}$, which is the percentage ratio of mean load and initial peak load, is the useful index to evaluate stability of the crushing process and performance of the absorber. It is obtained from Eqn. (3);

$$
\eta_{\mathrm{f}}=100\left(\mathrm{P}_{\mathrm{m}} / \mathrm{P}_{\mathrm{i}}\right)
$$

where the peak load $\left(\mathrm{P}_{\mathrm{i}}\right)$, which is commonly maximum load, is the initial highest load in the loaddisplacement curve. Mean crushing stress, $\sigma_{\mathrm{m}}$, which is another parameter to follow stress formation during crushing process, is found from following equation;

$$
\sigma_{\mathrm{m}}=\mathrm{P}_{\mathrm{m}} / \mathrm{A}
$$

where $A$ is the original cross-sectional area. Specific energy absorption, $\mathrm{E}_{\mathrm{s}}$ is the most important parameter to evaluate crushing characteristics of the material. It is the absorbed energy per unit mass of crushing sample and calculated with Eq. (5);

$$
E_{s}=\frac{E}{m_{\text {crush }}}=\frac{\int_{S_{i}}^{S_{f}} P(s) d s}{m_{\text {crush }}}
$$

\section{Results and Discussion}

\subsection{Load-displacement response and failure modes}

Load-displacement curve is the one of the main factors that gives the information about crash. The axial load-displacement curves with different fiber orientation angles and photographs during crushing history were presented in Figures 6 and Figure 7, respectively. As seen from figures, all samples had progressive crushing with high energy absorption and good reproducibility. The samples having $\pm\left(40^{\circ}\right)$ fiber orientations showed the stable progressively crushing process with parallel-to-fiber crack propagation caused from transverse shear and lamina bending (brittle fracturing). Because of that reason, it had the maximum load carrying capacity and bigger area under amongst curves. The samples with $\pm\left(55^{\circ}\right)$ and $\pm\left(70^{\circ}\right)$ fiber orientations had the similar cyclic characteristics and crushing history which were progressive end crushing with splaying 
fibers to outward. Crushing modes of them were detected as lamina bending (Farley \& Jones, 1992).

Figure 6: Load-displacement response

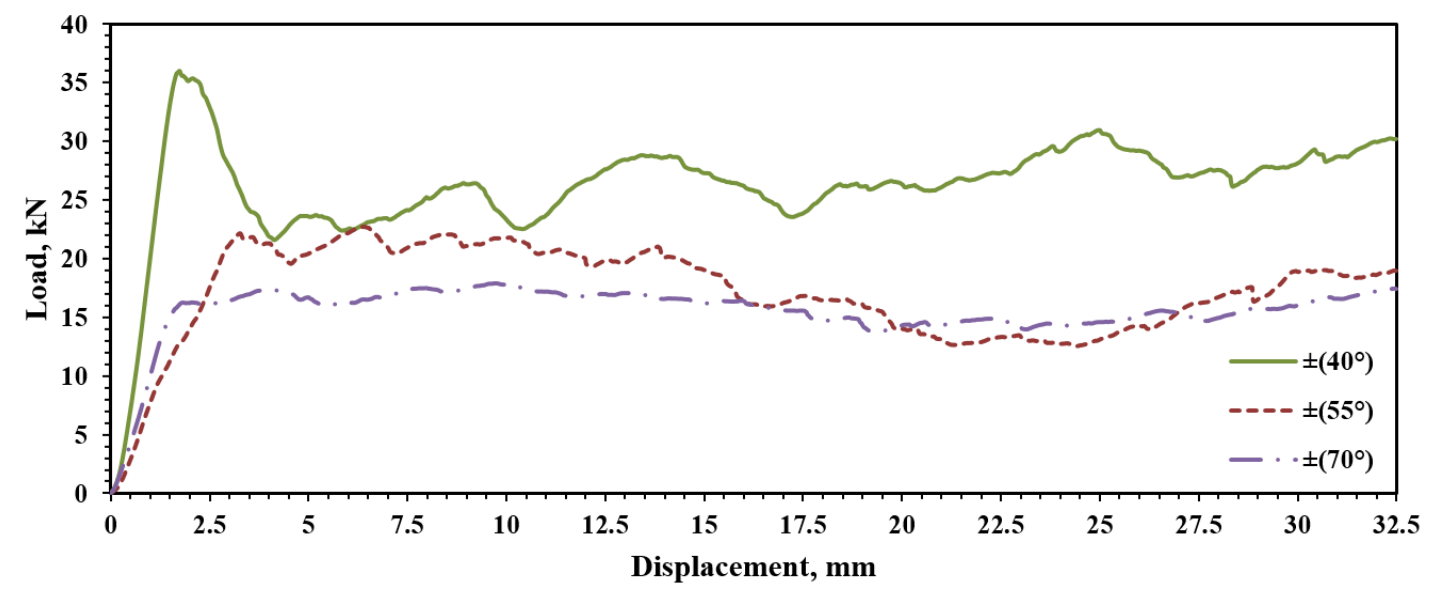

Figure 7: Crushing history

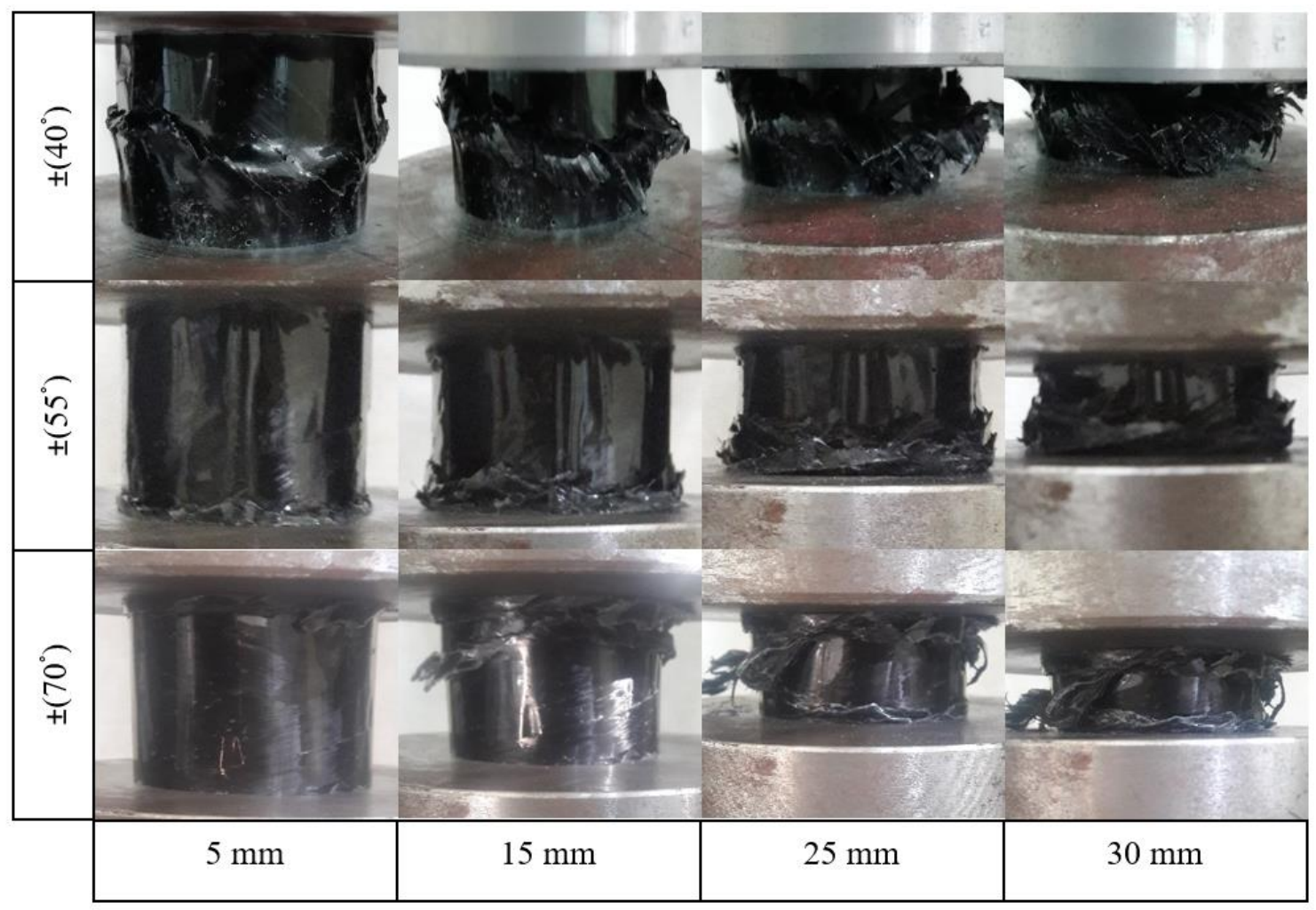

As seen from Figure 8, less debris were gradually produced when increasing fiber orientation. 
This can be related to increasing circumferential stiffness which could give a positive contribution to enhance the resistance to interlaminar crack growth [Wang et al., 2016,]. For smaller angles, interlaminar cracks propagated easily along longitudinal direction and form long crack length. Nevertheless, the samples showed the short interlaminar crack length longitudinally since parallelto-fiber cracking fact when pipe had bigger fiber orientation. Furthermore, the combination of fiber debonding, matrix fragmentation, delamination and fiber breakage of failures were observed from crushed shapes.

Figure 8: Samples after crushing

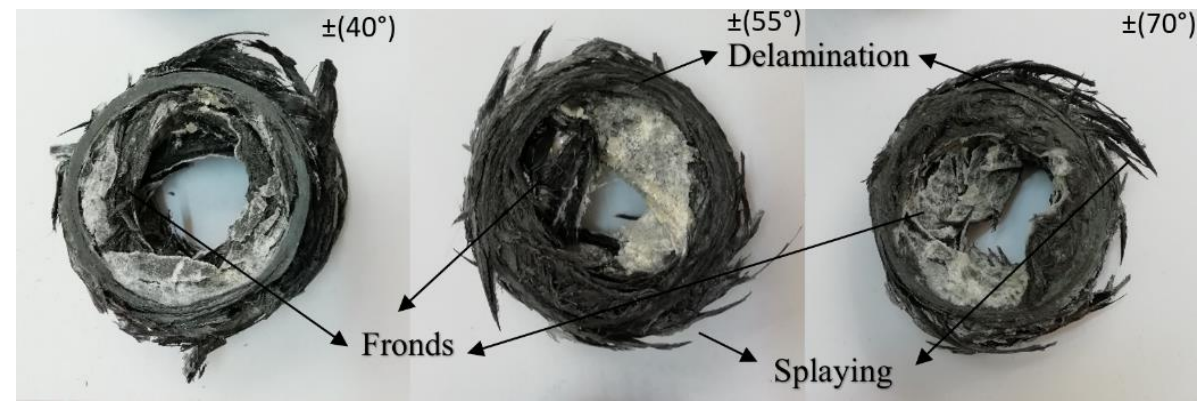

\subsection{Crushing load efficiency}

Initial peak load is a crucial parameter to understand crushing failure process beginning and also is related directly to the structure and human safety (Liu et al., 2014). The sample with $\pm\left(40^{\circ}\right)$ fiber orientation of $35.98 \mathrm{kN}$ value was achieved as maximum initial peak load, while minimum one was $16.69 \mathrm{kN}$ for $\pm\left(70^{\circ}\right)$ fiber orientation as indicated in Figure 9. Mean crushing load represents the average value of each load application in post-crushing stage, is a good indicator of overall energy absorption capability of pipes (Chiu et al., 2015). The sample with $\pm\left(40^{\circ}\right)$ fiber orientation had the maximum mean crushing load as $26.74 \mathrm{kN}$ due to brittle fracturing crushing mode. The bigger angle gave the better load carrying capacity since fiber was approached to loading direction.

Figure 9: Loading characteristics

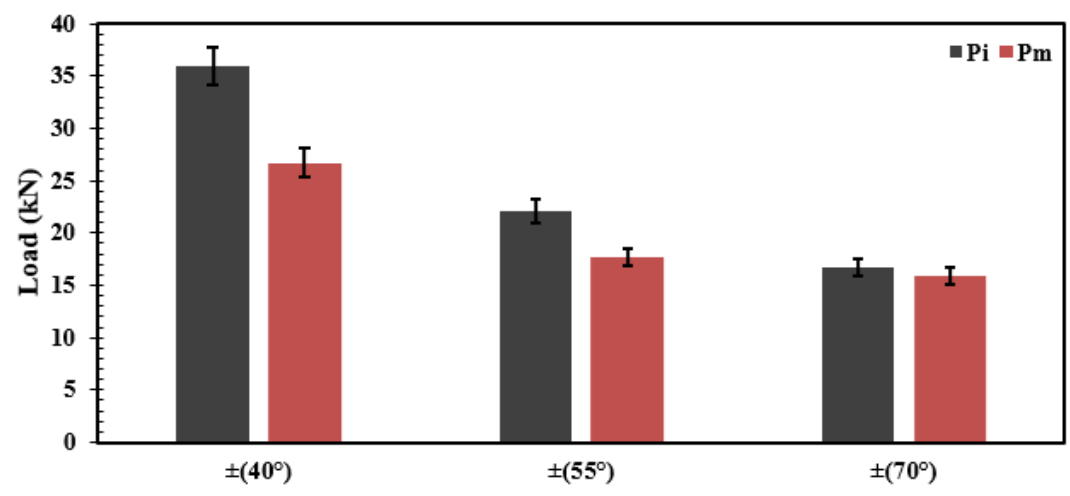


Crushing load efficiency which is the ratio of mean load and initial peak load, is the useful index to evaluate stability of the crushing process (Planivelu et al., 2010) and performance of the absorber (Kim et al., 2011). The higher crushing load efficiency, which means increase in energy absorption, is desired to get minimum casualties in the crash event. As seen from Figure 10, which represents the crushing load efficiency fro each configuration, the sample of $\pm\left(70^{\circ}\right)$ fiber orientation with $95.68 \%$ gave the better crushing load efficiency as $28.75 \%$ than $\pm\left(40^{\circ}\right)$.

Figure 10: Crushing load efficiency

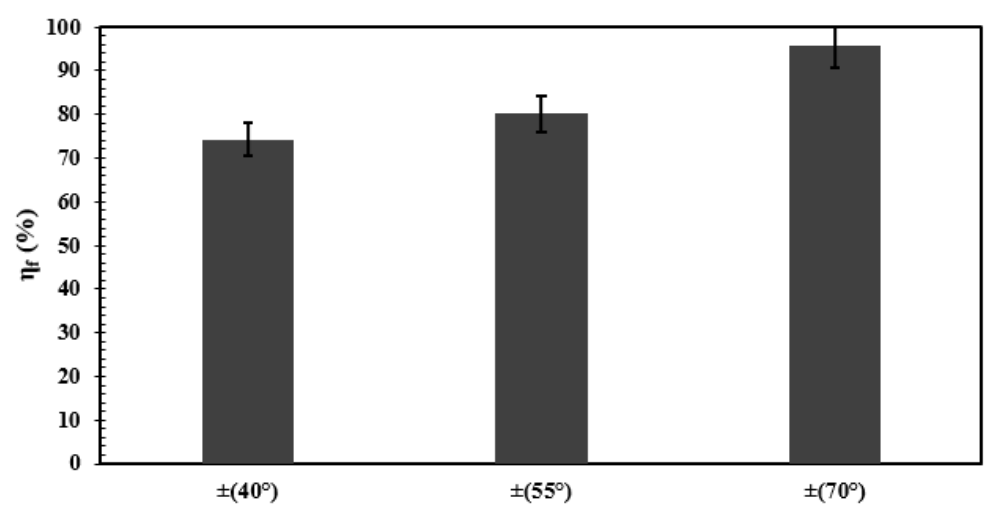

\subsection{Energy absorption}

Total energy absorption, which is the area under load-displacement curve, was presented in Figure 11. The sample of $\pm\left(40^{\circ}\right)$ fiber orientation had the maximum energy absorption as $822.75 \mathrm{~J}$. Also, $\pm\left(55^{\circ}\right)$ fiber orientation showed the improvement in $12.8 \%$ according to $\pm\left(70^{\circ}\right)$ fiber orientation. However, specific energy absorption instead of total energy should be noted because of mass consideration. Figure 12 representing specific energy absorption results provides the reliable information to be understandable about energy absorption. The maximum specific absorbed energy as $47.02 \mathrm{~J} / \mathrm{g}$ was found from the sample with $\pm\left(40^{\circ}\right)$ of fiber orientation. Specific energy absorption tends to gradually decrease trend results which are consistent with literature studies (Wang et al., 2016 - Mahdi et al., 2014). This situation can be explained by approaching the fiber orientation to loading direction which shows maximum strength. Furthermore, all samples had higher specific energy absorption than traditional aluminum pipe of $12 \mathrm{~J} / \mathrm{g}$ (Xin et al., 2019). This proves that the composite pipes are promising candidates to improve crashworthiness of structures (Tarakcioglu et al., 2005). 
Figure 11: Total energy absorption

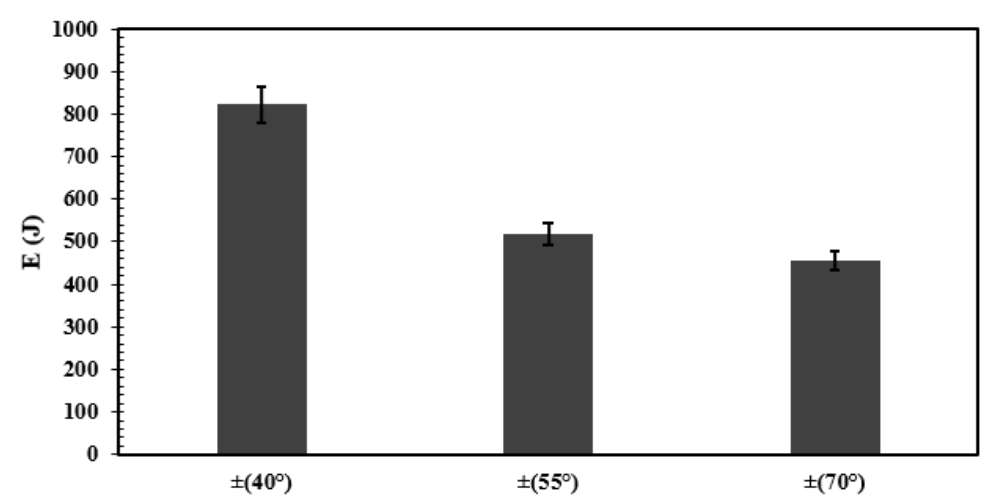

Figure 12: Specific absorbed energy

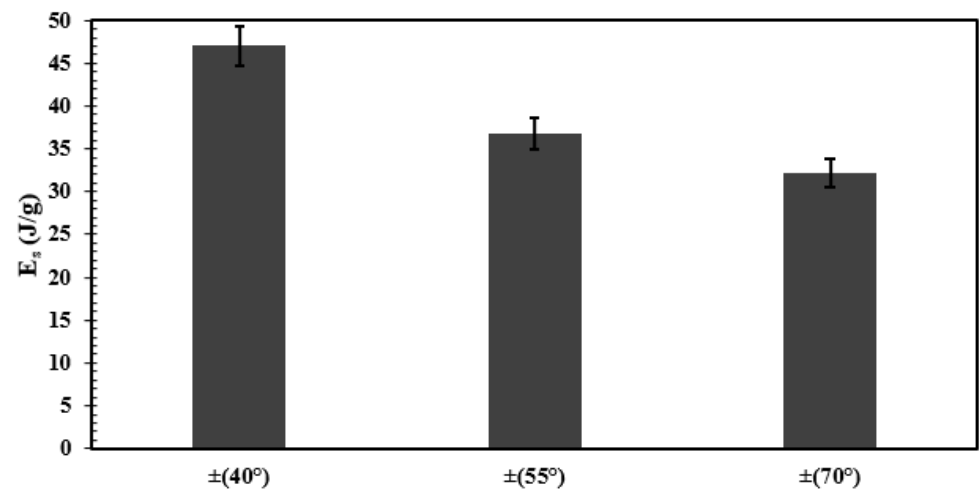

The characteristic parameters and mass information belong to axially crushed samples, which include initial peak load, mean crushing load, crushing load efficiency, mean crushing stress, total absorbed energy, specific energy absorption and crushing modes were given in Table 2. Differently from previous results, mean crushing stress decreased with increase in fiber orientation. $\pm\left(40^{\circ}\right)$ fiber orientation angle with $74.45 \mathrm{MPa}$ gave the stress result was 1.67 times of the $\pm\left(70^{\circ}\right)$ fiber orientation's value.

Table 2: Crashworthiness parameters of carbon fiber reinforced composite pipes

\begin{tabular}{|c|c|c|c|c|c|c|c|c|}
\hline Angle $\left(^{\circ}\right)$ & $\mathrm{M}(\mathrm{g})$ & $\mathrm{P}_{\mathrm{i}}(\mathrm{kN})$ & $\mathrm{P}_{\mathrm{m}}(\mathrm{kN})$ & $\eta_{\mathrm{f}}(\%)$ & $\begin{array}{c}\sigma_{\mathrm{m}} \\
(\mathrm{MPa})\end{array}$ & $\mathrm{E}(\mathrm{J})$ & $\mathrm{Es}(\mathrm{J} / \mathrm{g})$ & Crushing Mode \\
\hline$\pm\left(40^{\circ}\right)$ & 17.5 & 35.98 & 26.74 & 74.32 & 74.45 & 822.75 & 47.02 & Brittle fracturing \\
\hline$\pm\left(55^{\circ}\right)$ & 14.07 & 22.10 & 17.71 & 80.14 & 49.31 & 518.18 & 36.83 & Lamina bending \\
\hline$\pm\left(70^{\circ}\right)$ & 14.19 & 16.69 & 15.96 & 95.68 & 44.45 & 456.75 & 32.20 & Lamina bending \\
\hline
\end{tabular}

\section{Conclusions}

The effects of fiber orientation angle on the crashworthiness characteristics of the carbon fiber reinforced composite pipes fabricated by filament winding were experimentally examined. The main conclusions from this studies can be summarized as follows: 
- Maximum fiber mass content as $57.22 \%$ was obtained from $\pm\left(40^{\circ}\right)$ fiber orientation.

- $\quad$ All samples had progressive crushing with high energy absorption and good reproducibility for all fiber orientations.

- Increase in orientation angle resulted with inner and outer irregular splaying behaviors of the fibers. The combination of fiber debonding, matrix fragmentation, delamination and fiber breakage of failures were observed in most samples as seen on crushed shapes.

- Decrease in fiber orientation angle resulted with the increase in total energy absorption, specific absorbed energy, mean crushing stress, initial and mean crushing loads. However, it resulted with the decrease tendency in crushing load efficiency.

- $\quad$ The maximum specific absorbed energy as $47.02 \mathrm{~J} / \mathrm{g}$ was found from the sample with $\pm\left(40^{\circ}\right)$ of fiber orientation.

In conclusion, all samples had higher specific energy absorption than traditional aluminum pipe of $12 \mathrm{~J} / \mathrm{g}$. This proves that the composite pipes are promising candidates to improve crashworthiness of structures.

\section{Acknowledgment (TNR 12pt. bold)}

This paper is an output of the science project under grant number of MF. DT. 16. 13 thanks to Gaziantep University Scientific Research Center (BAP).

\section{References (TNR 14pt., bold)}

Misri, S., Ishak, M. R., Sapuan, S. M., \& Leman, Z. (2015). The effect of winding angles on crushing behavior of filament wound hollow kenaf yarn fibre reinforced unsaturated polyester composites. Fibers and Polymers, 16(10), 2266-2275.

Wang, Y., Feng, J., Wu, J., \& Hu, D. (2016). Effects of fiber orientation and wall thickness on energy absorption characteristics of carbon-reinforced composite tubes under different loading conditions. Composite Structures, 153, 356-368.

Mahdi, E., Hamouda, A. A., \& Sebaey, T. A. (2014). The effect of fiber orientation on the energy absorption capability of axially crushed composite tubes. Materials \& Design (19802015), 56, 923-928.

Jia, X., Chen, G., Yu, Y., Li, G., Zhu, J., Luo, X., ... \& Hui, D. (2013). Effect of geometric factor, winding angle and pre-crack angle on quasi-static crushing behavior of filament wound CFRP cylinder. Composites Part B: Engineering, 45(1), 1336-1343.

Farley, G. L., \& Jones, R. M. (1992). Crushing characteristics of continuous fiber-reinforced composite tubes. Journal of composite Materials, 26(1), 37-50.

Liu, Q., Xing, H., Ju, Y., Ou, Z., \& Li, Q. (2014). Quasi-static axial crushing and transverse bending of double hat shaped CFRP tubes. Composite Structures, 117, 1-11.

Chiu, L. N., Falzon, B. G., Ruan, D., Xu, S., Thomson, R. S., Chen, B., \& Yan, W. (2015). Crush responses of composite cylinder under quasi-static and dynamic loading. Composite Structures, 131, 90-98. 
Palanivelu, S., Van Paepegem, W., Degrieck, J., Van Ackeren, J., Kakogiannis, D., Van Hemelrijck, D., ... \& Vantomme, J. (2010). Experimental study on the axial crushing behaviour of pultruded composite tubes. Polymer testing, 29(2), 224-234.

Kim, J. S., Yoon, H. J., \& Shin, K. B. (2011). A study on crushing behaviors of composite circular tubes with different reinforcing fibers. International Journal of Impact Engineering, 38(4), 198-207.

Xin, Z., Duan, Y., Zhou, J., \& Xiao, H. (2019). Effect of tailored plies on the energy absorption capability of square CFRP tubes with discontinuous fibers. Composite Structures, 209, 150159.

Tarakçioğlu, N., Gemi, L., \& Yapici, A. (2005). Fatigue failure behavior of glass/epoxy \pm 55 filament wound pipes under internal pressure. Composites science and technology, 65(3-4), 703-708. 